\title{
Letter to Editor on a Rare Central Venous Catheter Malposition
}

\author{
Jason Lie $^{1, *} ;$ Manjula Yadagiri ${ }^{1}$; Catherine Aspinall ${ }^{1}$ \\ ${ }^{1}$ Department of Anaesthesia, Royal Albert Edward Infirmary, Wigan, UK \\ ${ }^{*}$ Corresponding author: Jason Lie, Specialty Trainee (ST6) in Anaesthesia, Department of Anaesthesia, Royal Albert Edward Infirmary, Wigan, UK. Tel: +44-7795212989, Fax: +44- \\ 1942244000, E-mail: jasonlie@doctors.org.uk
}

Received: May 26, 2014; Revised: June 20, 2014; Accepted: July 6, 2014

Keywords:Central Venous Catheter; Complications; Anesthetics, intravenous

\section{Dear Editor,}

We read A Rare Central Venous Catheter Malposition: A Case Report by Moeinipour et al. (1) with interest. Insertion of central venous catheters (CVCs) is without a doubt an essential component of both peri-operative and critical care monitoring and management (2). It is also considered as a fundamental skill to achieve Certificate of Completion of Training for any anaesthetic trainees in the United Kingdom (3). Insertion of CVCs is associated with complications in more than $15 \%$ of patients, mainly mechanically, from infection and from thromboembolic events (4). Hence, the importance of correct positioning of CVCs could not be undermined as malposition could lead to lethal consequences. There is currently no quoted incidence of malposition of central venous catheters into the left internal mammary (thoracic) vein from the literature. We also would like to report a rare case of a 69-year-old female who had a left internal jugular vein quad-lumen CVC inserted for venous access and iontropic support during her admission to the critical care unit. Left internal jugular vein was chosen to free up the right internal jugular vein for renal dialysis line. Apart from mild resistance when feeding the guide wire, the insertion was uneventful: full aseptic technique under ultrasound, first pass, seldinger technique using J-guide wire and blood was easily aspirated from all 4 lumen. Malposition was identified on the post-procedure chest $\mathrm{x}$-ray with the catheter lying on the left side, parallel to the tracheal shadow, under the level of the carina (see Figure 1). This line was used without complications after initial hesitancy about its location. Subsequently, a renal dialysis line was inserted without any difficulties under ultrasound to the right internal jugular vein in the correct position (again checked by chest x-ray). The malposition was identified by non-contrast Computed Tomography (CT).

Both of these cases lead us to believe that the incidence

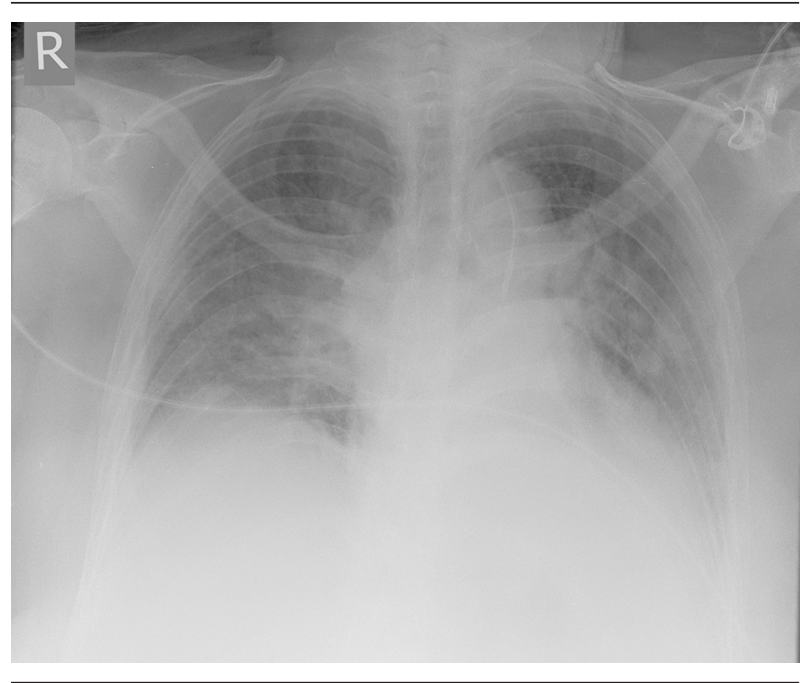

Figure 1. A Chest X-ray showing the malposition of a left internal jugular central venous catheter down the left internal mammary (thoracic) vein

of this type of malposition may be more common than we think. It emphasises the importance to appreciate the anatomy of the left internal jugular vein and its course to the superior vena cava. In addition, during the insertion of CVCs to the left internal jugular vein, we should pay extra attention to ensure that we lead with the guide wire and catheter with the bevel aiming towards the right hand side to ensure it aim towards the right subclavian vein and therefore avoid turning into the left internal mammary (thoracic) vein. Resistance to guide wire insertion should raise a high index of suspicion for potential malpositioning. Finally, apart from the left internal mammary (thoracic) vein, another rare malposition of CVCs into a duplicated left-sided superior vena cava is also possible. A duplicated left-sided superior vena cava is seen in $0.3-0.5 \%$ of the normal population and in $4.4 \%$ of those with congenital heart disease (5). This anatomical variation could only be diagnosed by contrast CT.

Copyright (C) 2014, Iranian Society of Regional Anesthesia and Pain Medicine (ISRAPM); Published by Kowsar. This is an open-access article distributed under the terms of the Creative Commons Attribution-NonCommercial 4.0 International License (http://creativecommons.org/licenses/by-nc/4.0/) which permits copy and redistribute the material just in noncommercial usages, provided the original work is properly cited. 


\section{Acknowledgements}

We would like to thank Dr. Choong Poon for providing his radiology input.

\section{Authors' Contributions}

Jason Lie and Manjula Yadagiri wrote up the manuscript. Catherine Aspinall provided proof-reading.

\section{References}

1. Moeinipour AA, Amouzeshi A, Joudi M, Fathi M, Jahanbakhsh S,
Hafez S, et al. A rare centralvenous catheter malposition: a case report. Anesth Pain Med. 2014;4(1).

2. Tomar GS, Tiwari AK, Jain DG, Chawla S, Sinha R. Central venous catheter rotation malposition: An unusual presentation. Indian J Anaesth. 2012;56(4):415-7.

3. The Royal College of Anaesthetists.. Completion of Training in Anaesthetics Basic Level. 2013. Available from: http://www.rcoa.ac.uk/ node 207 .

4. Alemohammad M. Central venous catheter insertion problem solving using intravenous catheter: technical communication. Tehran Univ Med Sci. 2013;70(11):724-8.

5. Pretorius PM, Gleeson FV. Case 74: right-sided superior vena cava draining into left atrium in a patient with persistent left-sided superior vena cava. Radiology. 2004;232(3):730-4. 